\title{
Standbunkt
}

Bioökonomie

\section{Wider das Wachstum der Grenzen}

\author{
Der technische Ansatz der Bioökonomie folgt der Idee, \\ dass Grenzen des Wachstums durch das Wachstum \\ der Grenzen überwunden werden können. Für eine gesellschaft- \\ liche Transformation muss die Bioökonomie einen anderen \\ Pfad einschlagen. \\ Von Ulrich Petschow
}

D er Begriff der bioeconomy wurde von Georgescu-Roegen geprägt. Dieser hat darauf verwiesen, dass sämtliche Ressourcen, so sie in ökonomischen Prozessen genutzt werden, letztlich degradiert werden. Er verweist damit auf die Grenzen des Wachstums und wird als einer der frühen Vertreter eines „Degrowth" Konzepts angesehen. Der Begriff der Bioökonomie, wie er heute auch im politischen Kontext zum Beispiel von Bioökonomiestrategien verwendet wird, geht zum einen von der Erkenntnis aus, dass die Nutzung der nicht erneuerbaren Ressourcen zu Ressourcenengpässen und Umweltproblemen führt. Der Lösungsansatz der Bioökonomie zielt daher, über die Nutzung der vielfältigen neuen technologischen Möglichkeiten der Manipulation der genetischen Ressourcen, auf die Eröffnung eines neuen technologischen Möglichkeitsraums ab.

Die Vorstellung eines umfassenden Paradigmenwechsels der Ressourcennutzung, nämlich dem Übergang von der Nutzung der nicht erneuerbaren Ressourcen zu der Nutzung erneuerbarer Ressourcen, wurde und wird im Kontext der Bioökonomiestrategien propagiert. Die Anerkennung dieser (Ressourcen-)Knappheiten führt zur Entwicklung von Strategien, die im Grundsatz zunächst davon ausgehen, dass im Wesentlichen technologische Innovationen vorangetrieben werden müssen, auch um der Ernährungssicherheit einer wachsenden Weltbevölkerung gerecht werden zu können. Die Herausforderungen entsprechender Übergänge sind extrem, wenn das bisherige Niveau an nicht erneuerbarer Ressourcennutzung durch erneuerbare Ressourcen aufrechterhalten werden soll. Zweifelsohne wird ein solcher Paradigmenwechsel zu erheblichen Nutzungskonflikten gerade auch um Flächen und Rohstoffe führen.

\section{Technische Lösung ...}

Dieses technikzentrierte Konzept wurde insbesondere vom Bioökonomierat der ersten Periode propagiert. Vereinfacht kann davon ausgegangen werden, dass das Erreichen der Grenzen der Belastbarkeit durch die Nutzung nicht erneuerbarer Ressourcen anerkannt wurde. Der Lösungsansatz der Bioökonomie zielt auf die Überwindung der noch vorhandenen Grenzen auf der biologischen Ebene, mithin der genetischen Manipulationen, von der weißen Biotechnologie, der synthetischen Biologie, aber auch von gene editing et cetera. Im Grundsatz folgt diese Idee der Vorstellung, dass die Grenzen des Wachstums durch das Wachstum der Grenzen überwunden werden können. Die neuen technologischen Potenziale in der Biologie sollen weiteres wirtschaftliches Wachstum ermöglichen. Begleitet wird dies allerdings durch eine ständig zunehmende Eingriffstiefe der Technologien und damit mehr oder weniger zwangsläufig verbunden auch durch eine Zunahme von technologischen Risiken.

Das dem Ansatz der Bioökonomie zugrunde liegende Effizienzparadigma zielt darauf ab, do more with less, also mit ei- nem geringeren Ressourceneinsatz, zu einem Mehr an materiellem Output zu kommen. Aus Sicht des Suffizienzparadigmas müsste dieser Satz allerdings so interpretiert werden, dass mit einem Weniger an Ressourcennutzung und zugleich geringerem Verbrauch materieller Gütern ein Mehr an gesellschaftlicher Wohlfahrt erreicht werden könnte. Letztere Interpretation liegt allerdings keiner der Bioökonomiestrategien $\mathrm{zu}$ grunde. Die Idee „im Einklang mit der Natur" wird interpretiert als eine weitere Zurichtung der "Natur“ entsprechend der Bedarfe einer auf Wirtschaftswachstum ausgerichteten Gesellschaft. Der gesellschaftliche Transformationsprozess, den die Bioökonomiestrategien anstreben, zielt vor allem auf die Verlängerung des Wachstumspfades und die Inanspruchnahme der Biologie für dieses Wachstum.

\section{... oder Instrument der Suffizienz?}

Eine Rückbesinnung auf die Interpretation des Begriffs der Bioökonomie von Georgescu-Roegen könnte die aktuellen Bioökonomiediskurse befruchten. Suffizienzstrategien, also Strategien des Weniger an Produkten und Verbräuchen stehen nicht im Fokus. Eine zukunftsfähige Bioökonomiestrategie sollte den Fokus sehr viel stärker auf Suffizienzund Konsistenzansätze legen und soziale Innovationen sehr viel stärker in den Vordergrund stellen und vor allem weitgehende Entkopplungen von Ressourcenverbräuchen (gleich ob nicht erneuerbare oder erneuerbare Ressourcen) von gesellschaftlichen Entwicklungsprozessen anstreben, ohne eine dramatische Erhöhung der technologischen Eingriffstiefe und der damit verbundenen Risiken.

AUTOR + KONTAKT

Ulrich Petschow leitet das Forschungsfeld Umweltökonomie und Umweltpolitik am Institut für ökologische Wirtschaftsforschung (IÖW).

Institut für ökologische Wirtschaftsforschung, Potsdamer Str. 105, 10785 Berlin. Tel.: +4930 884594-0 E-Mail: ulrich.petschow@ioew.de 